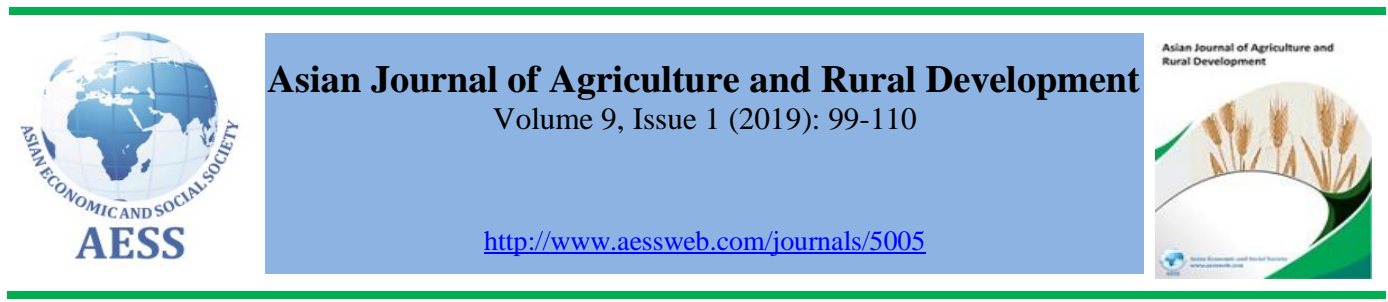

\title{
SOME RURAL ATTRACTIONS WHICH ATTRACT TOURISTS
}

(iD) Shu-Yi Chi ${ }^{\mathrm{a}}$ in, ${ }^{\mathrm{a}}$ Department of Applied Economics, National Chung Hsing

\section{Biing-Wen}

Huang ${ }^{a}$,

Han Xing Luo

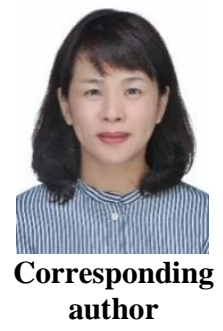

\section{ARTICLE HISTORY:}

Received: 05-Mar-2019

Accepted: 13-May-2019

Online Available: 03-Jun-

2019

\section{Keywords:}

Rural tourism,

Attraction,

Experiential value,

Just revisit,

Satisfaction

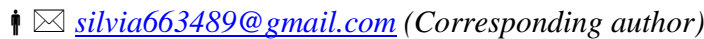

University, Taichung, Taiwan, (R.O.C).

author

\begin{abstract}
Developing rural tourism is a comprehensive strategy for improving the rural economy. The Structure Equation Model (SEM) approach was applied to test how attraction and experiential values of a rural region affect the tourists' satisfaction and their decision to revisit. After interviewing 353 tourists during their trip to Hakka County, Miaoli, Taiwan, the new finding of this study is that rural life and culture are more attractive than rural scenery to tourists. This implies a strong preference for tourists to experience agricultural knowledge and engage with rural life and farming work. Furthermore, the experiential response generated from the indirect mediation effect of satisfaction had a significant effect, supporting the concept that satisfaction brings additional experiential values to the intentions of tourists to revisit and thus creates more revisit opportunities to those tour sites.
\end{abstract}

\begin{abstract}
Contribution/ Originality
The study explores that rural life and culture are more attractive than rural scenery to tourists which implies the tourists' strong preference for experiencing agricultural knowledge and engaging with rural life. Further, the indirect mediation effect of satisfaction had a significant effect on supporting the concept that satisfaction brings additional experiential values to tourists' intention to revisit and thus creates more revisit opportunities to those tour sites.
\end{abstract}

DOI: 10.18488/journal.1005/2019.9.1/1005.1.99.110

ISSN (P): 2304-1455/ISSN (E):2224-4433

How to cite: Shu-Yi Chi, Biing-Wen Huang and Han Xing Luo (2019). Some rural attractions which attract tourists. Asian Journal of Agriculture and Rural Development, 9(1), 99-110.

(C) 2019 Asian Economic and Social Society. All rights reserved. 


\section{INTRODUCTION}

Rural tourism refers to tourist activities in rural areas or non-urban territory where tourists engage in leisure and rural pursuits with aspects of emotional and spiritual experiences (Jepson and Sharpley, 2015; Liu, 2008; Oppermann, 1996). Since emotional experiences in rural development influence tourist preferences, the development of rural tourism has become the primary boosting momentum for the advancement of rural prosperity (Huang et al., 2016). This further helps to form the win-win strategies which not only benefit tourists for their satisfaction but also local residents which results in higher employment and income as well as better quality of life (Choenkwan et al., 2016).

However, aside from the expense incurred by the tourists themselves, the characteristics of tourist attractions, whether travel experiences can be shared or recommended via social media, and the likelihood that tourists will revisit tourist destinations in the future may be taken into account (Sameer et al., 2016). Accordingly, a rural area that lacks the potential for commercial images, a distinctive natural landscape, or a planned interactive environment may not appeal to tourists.

Of the many factors that affect consumers' decisions on tour destinations, attraction is seen as an inherent behavioral intention (Leiper, 1990). Tourist preferences for a tour destination typically exert a positive influence on tourist satisfaction, while the characteristics of different destinations create a diverse attraction network for tourists. In other words, rural attractions with distinctive characteristics, such as a farmers' auction market may appeal to tourists (Ea et al., 2015; Choenkwan et al., 2016; McKercher and Koh, 2017).

Based on consumer experiences, consumer value can be seen as an interactive and relativistic preference whose value lies not in its purchase but in the associated consumer experience (Holbrook and Hirschman, 1982; Holbrook, 1996; Pine and Gilmore, 1998; Simelane et al., 2016; Lee et al., 2017). Accordingly, creating memorable experiences for tourists has become a core value of the tourist industry (Knobloch et al., 2017). For tour business, providing a memorable tour and continuously developing new tourist products will generate positive word-of-mouth communication (Knobloch et al., 2017) and will enhance their competitiveness and sustainability (Ritchie et al., 2011). Because the cost of attracting potential tourists is often higher than that of tourists who already have experience in the tour, the development of tourist attractions is increasingly dependent on those revisit tourists. Thus, an insight into the revisit intentions of tourists has become an important research topic (Assaker et al., 2011; Chew and Jahari, 2014).

In addition, investigations of rural tourism have shown that satisfaction and revisit frequency have an impact on tourists' revisit intentions (Antón et al., 2017). Therefore intense analysis of revisit intention is also regarded as a key economic factor that could affect the tourist industry as well as rural tourism (Jang and Feng, 2007). While numerous existing tourist studies focus more on destination characteristics, experiences, and satisfaction, the mediating effect of satisfaction, which is a notable feature of rural tourist research, is rarely discussed. Based on rural tourist perspectives, this study plans to investigate related cases of rural leisure tourism of Taiwan and to explore how attraction and experiential values in terms of tour projects and attractive products affect tourist intentions to revisit the same sites. The findings could be used as a comprehensive reference for rural communities in relation to designing tourist activities and experiences to further steer tourist development in regenerating rural communities. 


\section{METHODS}

\subsection{Research Framework}

\subsubsection{Attraction}

Attraction refers to the motivation of internal force (inherent behavioral force) that affects consumers' decisions and pushes them toward attractions (Leiper, 1990); this is also known as the "first power" in tourist development (Gunn, 1997). Attraction is chiefly focused on culture, nature, activities, recreation, and entertainment, and tourists are also attracted by natural scenery, buildings, artificial landscapes, and special festivals (Swarbrooke, 2002). Rural attractions with distinctive characteristics appeal greatly to tourists (Choenkwan et al., 2016), while attractive tourist markets also draw consumers to visit (McKercher and Koh, 2017).

The development of rural tourism is also one of the winning strategies for potential agriculture enhancement (Choenkwan et al., 2016). In their study, Cai and Combrink (2000) came up with the push-pull theory of tourist motivation. According to that theory, the tourist attraction of rural destinations comprises the push factors that motivate tourists to travel, such as education, physiology, health, social events, and conspicuousness, while the pull factors include other aspects that appeal to tourists; for example, natural landscapes, rural life and culture, and convenient transportation.

\subsubsection{Experiential value}

Experiential value is essentially untouchable, but the perceptions consumers gain from the process of experiencing is long-lasting (Pine and Gilmore, 1998). Based on consumer research, people tend to be fascinated by intangible experiences that benefit them mentally; for example, experiencing a feeling of fun (Holbrook and Hirschman, 1982; Holbrook, 1996), a sense of happiness, a desire to flee, or the urge to enjoy a fresh impetus (Weinberger et al., 2017).

Such "experiences" learned through experience could be considered the most popular "product" of the tourist market (Knobloch et al., 2017). Through the process of experiencing, consumers are guided to make accurate decisions in the presence of a credible behavior which allows them to live a meaningful life as a result (Schmitt and Zarantonello, 2013). Through authentic experiences, tourists will gain personal experiential values from various interactions in the course of their travel (Sheth et al., 1991).

The experiential perceptions of consumers typically involve five aspects: namely, sense (sensory experience), feel (affective experience), think (intellectual experience), act (behavioral experience), and overall (Schmitt and Zarantonello, 2013). Furthermore, these experiential values also extend to consumers' return on expenditure, the quality of service they experience, and their aesthetic perceptions and pleasure (Mathwick et al., 2001).

\subsubsection{Satisfaction and revisit intention}

In assessing the important aspects of consumers' experiential values, satisfaction is measured based on the tourists' expectations of their scheduled travel tours and their actual perceptions of their destination after they arrive (Del Bosque and Martin, 2008). Zeithaml et al. (1996) defined willingness to revisit a destination as the intention to return to a place but also the willingness to recommend it; in other words, it amounts to the cognitive difference between consumers' prepurchase expectations and their actual post-purchase perceptions.

Westbrook (1987) suggests that satisfaction is usually the mediating variable of the consumers' willingness to repurchase. Lin et al. (2003) explored tourist revisit intentions in relation to scenic coastal areas with this framework. The results supported that satisfaction positively affects tourists' 
behavioral intentions, deepens their perceptions of the tourist experience, and significantly affects tourists' intentions to revisit a destination.

\subsection{Hypotheses}

Two approaches are adopted to explore the travel value of tourists in this study. One is the investigation of interests combined with consumer values, and the second one is the concept of experiential values, which has drawn increasing attention among tour operators recently (Komppula and Gartner, 2013).

Experiential marketing has also been applied by many researchers to measure tourist experiences by influencing tourist satisfaction (Cai and Combrink, 2000; Shen et al., 2005). Leask et al. (2013) suggested that to meet the needs of all generations for traveling, agents may adopt segment-based experiential marketing strategies to attract tourists.

Sameer et al. (2016) showed that tourist satisfaction brings about tourist loyalty, and this affection toward the destination will exert a direct influence on tourist satisfaction and their intentions to recommend the attractions. If a tourist's image in accordance with the experience is pleasant, this will then increase the tourist's intention to revisit the destination. Although destination attributes play a key role with tourists choosing a place to visit, how to fulfill the typical travel wishes of the tourists and present enjoyable travel experience are more important with regard to meeting tourists' expectations (Gannon et al., 2017).

This study evaluates the relationships between experiential values, attraction, satisfaction, and tourist revisit intentions based on four hypotheses as follows:

Hypothesis 1: Attraction positively influences experiential values.

Hypothesis 2: Experiential values positively influences satisfaction.

Hypothesis 3: Experiential values positively influence the tourists' intention to revisit.

Hypothesis 4: Satisfaction positively influences the tourists' intention to revisit.

We also plan to examine the mediating effect of tourist satisfaction between experiential values and revisit intention. The research framework is shown below (see Figure 1).

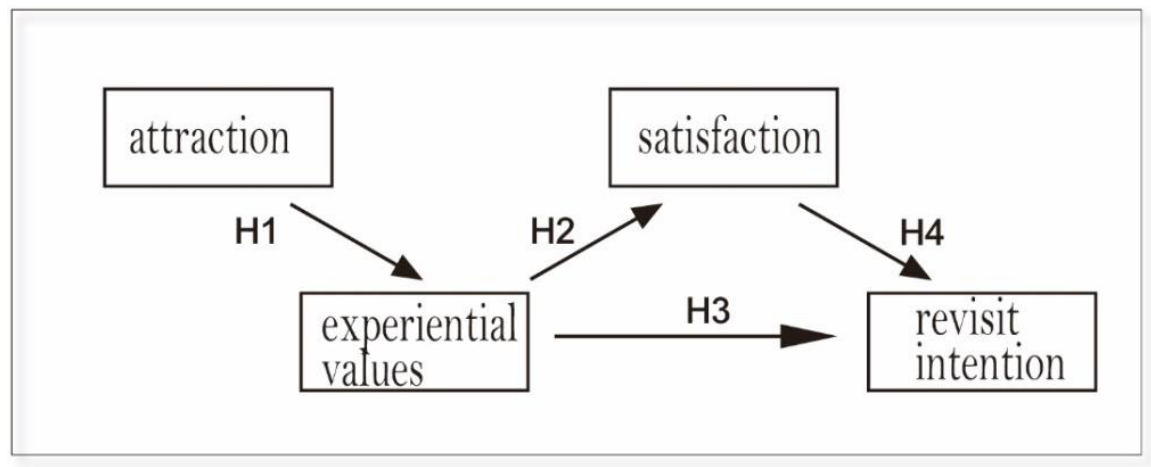

Figure 1: Research framework

\subsection{Data collection and analysis}

The 353 questionnaires were collected during July and September of 2015 with an effective rate of $88.25 \%$. In summary, many of the tourists $(195 ; 55.2 \%)$ were from central Taiwan (see Table 1 ). Most of the tourists were female, at $248(70.3 \%)$, while 128 tourists stated that they were aged 45 $65(36.3 \%)$. A total of 140 tourists reported having a bachelor degree (39.7\%), and 101 were engaged in business $(28.6 \%)$. Income of less than 25K NTD per month was claimed by 163 
(46.2\%), while 168 stated that they travelled with their families (47.6\%). 178 tourists $(50.4 \%)$ travelled less than three times for the number of domestic travel trips taken in 2014.

Table 1: Descriptive statistics of the sample $(\mathrm{N}=353)$

\begin{tabular}{|c|c|c|c|}
\hline Category & Item & Number & Percentage (\%) \\
\hline \multirow{2}{*}{ Residence } & North & 158 & 44.8 \\
\hline & Central & 195 & 55.2 \\
\hline \multirow{2}{*}{ Gender } & Male & 105 & 29.7 \\
\hline & Female & 248 & 70.3 \\
\hline \multirow{6}{*}{ Age } & Under 14 & 40 & 11.3 \\
\hline & $15-24$ & 35 & 9.9 \\
\hline & $25-34$ & 47 & 13.3 \\
\hline & $35-44$ & 30 & 8.5 \\
\hline & $45-64$ & 128 & 36.3 \\
\hline & 65 and above & 73 & 20.7 \\
\hline \multirow{5}{*}{ Education } & Elementary and below & 44 & 12.5 \\
\hline & Junior high school & 46 & 13.0 \\
\hline & Senior high school & 100 & 28.3 \\
\hline & College & 140 & 39.7 \\
\hline & Master and above & 23 & 6.5 \\
\hline \multirow{4}{*}{$\begin{array}{l}\text { Times of domestic travel in } \\
2014\end{array}$} & $1-3$ & 178 & 50.4 \\
\hline & $4-6$ & 153 & 43.4 \\
\hline & $7-9$ & 21 & 6.1 \\
\hline & 10 or above & 21 & 6.1 \\
\hline \multirow{6}{*}{ Occupation } & Student & 76 & 21.5 \\
\hline & Business & 101 & 28.6 \\
\hline & Government official & 17 & 4.8 \\
\hline & Agriculture & 2 & 0.6 \\
\hline & Retirement & 97 & 27.5 \\
\hline & Other & 60 & 17.0 \\
\hline \multirow{5}{*}{ Monthly income } & Less than $25 \mathrm{~K}$ & 163 & 46.2 \\
\hline & $25 \mathrm{~K}-40 \mathrm{~K}$ & 101 & 28.6 \\
\hline & $40 \mathrm{~K}-55 \mathrm{~K}$ & 53 & 15.0 \\
\hline & $55 \mathrm{~K}-70 \mathrm{~K}$ & 18 & 5.1 \\
\hline & $70 \mathrm{~K}$ and above & 18 & 5.1 \\
\hline \multirow{7}{*}{ Travel companion } & Alone & 13 & 3.7 \\
\hline & Family & 168 & 47.6 \\
\hline & Couple & 5 & 1.4 \\
\hline & Friend & 140 & 39.7 \\
\hline & Coworker & 9 & 2.5 \\
\hline & Other & 18 & 5.1 \\
\hline & None & 22 & 6.2 \\
\hline
\end{tabular}

\section{RESULTS}

\subsection{Indicator analysis and reliability analysis}

To check whether discrimination was associated with the indicators in the questionnaire, an item analysis was first done before confirmatory factor analysis to examine the relevance of each indicator item in the questionnaire. Comparisons of extreme groups were used in the item analysis, and the samples were divided in a $27 \%$ to $73 \%$ split. A paired sample t-test was taken to check the discrepancy in the means of the indicators for the two groups. 
Results indicated that all the variables discriminated well. Subsequently, a reliability analysis was carried out to identify the internal consistency of the questionnaire, and modified indicators with a total correlation of lower than 0.50 were deleted from the scale. The Cronbach's $\alpha$ coefficients displayed in the reliability analysis of the latent variables were all over $0.80(0.84 \sim 0.90)$, and it can thus be inferred that this questionnaire is reliable. Descriptive statistics and reliability detection of the four latent variables of the model are shown in Table 2 below.

Table 2: Results of the reliability measure $(\mathrm{N}=353)$

\begin{tabular}{lcccc}
\hline Dimensions & Number of items & Mean & S. deviation & Cronbach's $\boldsymbol{\alpha}$ \\
\hline Attraction & 7 & 6.457 & 3.836 & 0.851 \\
Experiential value & 9 & 6.459 & 4.459 & 0.886 \\
Satisfaction & 7 & 6.472 & 3.875 & 0.900 \\
Revisit intention & 3 & 6.605 & 1.578 & 0.840 \\
\hline
\end{tabular}

\subsection{Confirmatory factor analysis (CFA)}

In this study, a modification index (MI) was used to delete the indicators whose standardized estimates were lower than 0.5 or which had high variance in order to improve the model fit. Goodness of fit (GFI), adjusted goodness of fit (AGFI), root mean square error of approximation (RMSEA), Tucker-Lewis index (TLI), and comparative fit index (CFI) were applied to measure the model fit in structural equation modeling (SEM) (Fan and Sivo, 2005). Table 3 shows the GFI analysis of the research model, where $\chi^{2} / \mathrm{DF}=1.864$, GFI $=0.929$, AGFI $=0.900$, RMSEA $=$ $0.050, \mathrm{TLI}=0.960$, and CFI $=0.966$. These statistics indicate that a good fit was achieved.

Table 3: Goodness-of-fit measures for the structural equation model

\begin{tabular}{lcc}
\hline Goodness-of-fit measure & Index & Criterion \\
\hline$\chi^{2} / \mathrm{DF}$ & 1.864 & $<3.0$ \\
GFI & 0.929 & $>0.80$ \\
AGFI & 0.900 & $>0.80$ \\
RMSEA & 0.050 & $<0.08$ \\
TLI & 0.960 & $>0.90$ \\
CFI & 0.966 & $>0.90$ \\
\hline
\end{tabular}

Notes: $\chi^{2}=$ chi-square, DF $=$ degree of freedom, GFI $=$ goodness-of-fit index, AGFI $=$ adjusted goodness-offit index, RMSEA = root mean square error of approximation, TLI = Tucker-Lewis index, CFI = comparative fit index, (+): acceptability

Three types of convergent validity in the measurement model are described as follows: (1) Factor loadings serving as index variables explain the correlation of each variable to the underlying factor. The larger the factor loadings, better the expression of the factors. The recommended factor loadings from the results ranged between 0.6 and 0.95 ; (2) Composite reliability (CR) is used to measure the internal consistency of the factor variables, and a CR value $>0.7$ is considered; and (3) Average variance extracted (AVE) is used to assess discriminant validity with an AVE $>0.5$ considered (Hair et al., 2013). As shown in Table 4, the CR in the four latent variables was between 0.831 and 0.896 , presenting good internal consistency. In addition, the AVE of the latent variables mostly reached the standard threshold of 0.5 or above. 
Table 4: Results of exploratory factor analysis of the standardized model

\begin{tabular}{|c|c|c|c|c|c|c|c|}
\hline \multicolumn{2}{|c|}{$\begin{array}{l}\text { Latent variables and measured } \\
\text { indicators }\end{array}$} & Estimate & SMC & SE & T-value & $\mathbf{C R}$ & AVE \\
\hline \multicolumn{6}{|c|}{ Attraction (engagement in rural tourism) } & 0.831 & 0.623 \\
\hline A6 & $\begin{array}{l}\text { Able to experience natural resources } \\
\text { (natural resources) }\end{array}$ & 0.753 & 0.567 & & & & \\
\hline A7 & $\begin{array}{l}\text { Able to experience rural life and } \\
\text { culture (life and culture) }\end{array}$ & 0.856 & 0.733 & 0.085 & $14.730^{* * *}$ & & \\
\hline A8 & $\begin{array}{l}\text { Able to experience rural landscape } \\
\text { resources (landscape resources) }\end{array}$ & 0.754 & 0.569 & 0.098 & $13.649^{* * *}$ & & \\
\hline \multicolumn{6}{|c|}{ Experiential values (experience gained from rural tour engagement) } & 0.847 & 0.499 \\
\hline $\mathrm{C} 1$ & $\begin{array}{l}\text { I perceived the beauty of rural areas } \\
\text { (sense of beauty) }\end{array}$ & 0.699 & 0.489 & & & & \\
\hline $\mathrm{C} 2$ & $\begin{array}{l}\text { I gained knowledge and pleasure } \\
\text { (pleasure) }\end{array}$ & 0.727 & 0.529 & 0.077 & $12.661^{* * *}$ & & \\
\hline B1 & $\begin{array}{l}\text { I felt sensual enjoyment (sensory } \\
\text { experience) }\end{array}$ & 0.694 & 0.482 & 0.078 & $12.130^{* * *}$ & & \\
\hline B2 & $\begin{array}{l}\text { I felt warmth and enthusiasm from } \\
\text { rural villages (affective experience) }\end{array}$ & 0.674 & 0.454 & 0.075 & $11.784^{* * *}$ & & \\
\hline B3 & $\begin{array}{l}\text { I gained knowledge about rural } \\
\text { industry (intellectual experience) }\end{array}$ & 0.756 & 0.572 & 0.074 & $13.149^{* * *}$ & & \\
\hline B4 & $\begin{array}{l}\text { I'm pining for rural life and activity } \\
\text { engagement (behavioral experience) }\end{array}$ & 0.732 & 0.536 & 0.085 & $12.753^{* * *}$ & & \\
\hline B5 & $\begin{array}{l}\text { I'll be more aware of rural tourism } \\
\text { development (overall experience) }\end{array}$ & 0.657 & 0.432 & 0.077 & $11.500^{* * *}$ & & \\
\hline \multicolumn{6}{|c|}{ Satisfaction (personal experience of this rural tour) } & 0.896 & 0.591 \\
\hline G2 & $\begin{array}{l}\text { I'm satisfied with the content } \\
\text { (experiencing content) }\end{array}$ & 0.838 & 0.702 & & & & \\
\hline G1 & $\begin{array}{l}\text { I'm satisfied with the environment } \\
\text { of the rural community (rural } \\
\text { environment) }\end{array}$ & 0.728 & 0.530 & 0.060 & $15.481^{* * *}$ & & \\
\hline G3 & $\begin{array}{l}\text { I'm satisfied with the schedule } \\
\text { (schedule arrangements) }\end{array}$ & 0.820 & 0.672 & 0.058 & $18.404^{* * *}$ & & \\
\hline G4 & $\begin{array}{l}\text { I'm satisfied with the safety of the } \\
\text { facilities on site (facility safety) }\end{array}$ & 0.670 & 0.449 & 0.063 & $13.850^{* * *}$ & & \\
\hline G5 & $\begin{array}{l}\text { I'm satisfied with the food and } \\
\text { beverage arrangements (catering } \\
\text { arrangements) }\end{array}$ & 0.733 & 0.537 & 0.055 & $15.619^{* * *}$ & & \\
\hline G7 & $\begin{array}{l}\text { I'm satisfied with the overall } \\
\text { activity (overall activity) }\end{array}$ & 0.810 & 0.656 & 0.052 & $18.070^{* * *}$ & & \\
\hline \multicolumn{6}{|c|}{ Tourist's intention to revisit } & 0.841 & 0.639 \\
\hline D1 & $\begin{array}{l}\text { I will participate in rural tourist } \\
\text { activities if there's a chance (revisit) }\end{array}$ & 0.741 & 0.549 & & & & \\
\hline D2 & $\begin{array}{l}\text { I'll recommend rural tourist } \\
\text { activities to my friends and family } \\
\text { (recommendation) }\end{array}$ & 0.831 & 0.691 & 0.073 & $14.763^{* * *}$ & & \\
\hline D3 & $\begin{array}{l}\text { I'll share the rural tourist experience } \\
\text { with my friends and family } \\
\text { (promotion) }\end{array}$ & 0.823 & 0.677 & 0.071 & $14.650^{* * *}$ & & \\
\hline
\end{tabular}

Note: $\mathrm{SMC}=$ squared multiple correlations; $\mathrm{SE}=$ standard error; $\mathrm{CR}=$ composite reliability; $\mathrm{AVE}=$ average variance extracted 
According to the correlation of the latent variables and measured indicators shown in Table 4, the primary attraction of rural tourism for tourists is being able to experience rural life and culture (A7), rural landscape resources (A8), and natural resources (A6), with a " $\beta$ " of $0.856,0.754$, and 0.753, respectively. This supports the findings of previous studies that rural attractions with distinctive characteristics are appealing to tourists (Choenkwan et al., 2016). The result also supports that rural life and culture are more attractive than rural scenery to tourists. Through Experiential values perspectives experience gained from rural tour engagement in intellectual experience (I gained knowledge about rural industry, B3, $\beta=0.756$ ), behavioral experience (I'm pining for rural life and activity engagement, B4, $\beta=0.732$ ), pleasure (I gained knowledge and pleasure, $\mathrm{C} 2, \beta=0.727$ ) are higher than sense of beauty (I perceived the beauty of rural areas, $\mathrm{C} 1$, $\beta=0.699$ ). And through Attraction perspectives engagement in rural tourism in life and culture (able to experience rural life and culture, $A 7, \beta=0.856$ ) is higher than landscape resources (able to experience rural landscape resources, $A 8, \beta=0.754$ ). Therefore the new finding of this study is that rural life and culture are more attractive than rural scenery to tourists. The experience types favored by tourists were knowledge (B3) and action (B4) activities, with $\beta$ value at 0.756 and 0.732 , respectively. This highlights the tourists' strong preference for experiencing agricultural knowledge and engaging with rural life and farming work. "Knowledge and Pleasure received from the rural tour" $(\mathrm{C} 2)$, with a " $\beta$ " of 0.727 was found to be the most prized experiential value for tourists during participation in rural tourism.

This suggests that tour agents need to add more pleasurable aspects to intellectual and behavioral experiential activities when arranging tour activities with high experiential values. Experiencing content (G2) and schedule arrangements (G3) attained a " $\beta$ " of 0.838 and 0.820 , respectively, which reflects satisfaction with rural tourism. Indicators D2 and D3, which present the willingness to recommend the tour to family and friends, and word of mouth earned the most recognition from consumers with a " $\beta$ " of 0.831 and 0.823 , respectively.

\subsection{Analysis of the structural model and hypothesis testing}

The empirical results are shown in Table 5. Attraction, experiential values, experiential values, and satisfaction are all positively influenced experiential values in $\mathrm{H} 1$, satisfaction in $\mathrm{H} 2$, tourists' intention to revisit in $\mathrm{H} 3$, and tourists' intention to revisit in $\mathrm{H} 4$ with $\beta$ values at $0.719,0.816$, 0.324 , and 0.508 , respectively. This result showed that all the hypotheses of this study were proven. In addition, the experiential value generated from the indirect mediating effect of satisfaction had a $\beta=0.414$ with the $t$-value at 0.738 , supporting the idea that satisfaction brings more experiential values to tourists' revisit intentions and creates more revisit opportunities as well. The direct and indirect effects are shown in Table 6 below.

Table 5: Results of the structural path and hypotheses

\begin{tabular}{llccc} 
& Structural path hypotheses & Standardized & T-value & Result \\
\hline H1 & Attraction $\rightarrow$ Experiential Values & 0.719 & $10.118^{* * * *}$ & supported \\
H2 & Experiential Values $\rightarrow$ Satisfaction & 0.816 & $12.349^{* * * *}$ & supported \\
H3 & Experiential Values $\rightarrow$ Revisit & 0.324 & $3.505^{* * *}$ & supported \\
& Intention & 0.508 & $5.418^{* * *}$ & supported \\
\hline
\end{tabular}

Notes: $* * *$ represents $\mathrm{p}<0.001$

Table 6: Direct and indirect effects

\begin{tabular}{clccc}
\hline & Structural path hypotheses & Direct effect & Indirect effect & Total effect \\
\hline H1 & Attraction $\rightarrow$ Experiential Values & 0.719 & - & 0.719 \\
H2 & Experiential Values $\rightarrow$ Satisfaction & 0.816 & - & 0.816 \\
H3 & Experiential Values $\rightarrow$ Revisit Intention & 0.324 & 0.414 & 0.738 \\
H4 & Satisfaction $\rightarrow$ Revisit Intention & 0.508 & - & 0.508 \\
\hline
\end{tabular}




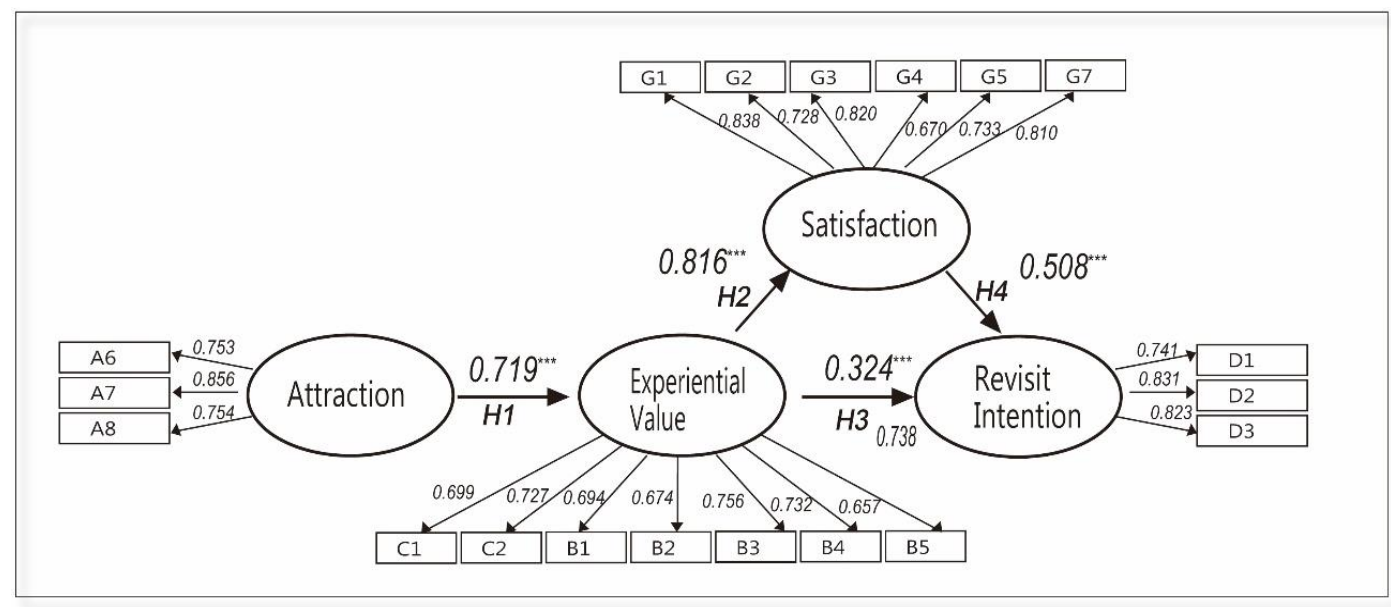

Figure 2: Empirical result of the structural model

\section{DISCUSSIONS}

This study proves that tourism attraction positively influences the tourists' experiential values and their intention to revisit rural tourism by using the linear structure method. In addition, the experiential response generated from the indirect mediation effect of satisfaction had a significant effect, supporting the notion that satisfaction brings additional experiential values to tourists' revisit intentions and thus creates more revisit opportunities to those tour sites. In the face of an increasingly stable tourism market, how to enhance the economic development of the community by enhancing the willingness of tourists to visit has become an important issue. This paper proposes the following strategies based on the results.

Enhance rural tourism by shaping the distinctive characteristics of rural culture. Rural communities should have a deep understanding of their own cultural attributes through regenerating activities in farming and living. Residents can develop traditional life and offer tourists a chance to appreciate details and aspects of the local culture in a new way.

Based on the diversity of agricultural products in the neighbouring rural communities, themebased activities can be undertaken to promote seasonal agricultural products, and the seasonal characteristics of the destination can be conveyed to the tourists during the tour to enhance tourist expectation of the next trip. Offering farming experience in this area should be considered. The farming activities provide pleasurable experiences to tourists through planting, weeding, or harvesting operation on the farms. The visitors' impression of the villages is enhanced by these interactions with the environment and community, and these involvements may mean they visit again.

Cater to tourists' experience for farming tour planning with more intellectual and behavioral experiences. Planning a tour involves choosing an appropriate tour module to satisfy the tourists' experiences of satisfaction. Moreover, our findings suggest that those revisited tourists feature activities in those farming experience with knowledge and field operation, which suggests that considering more activities of these types when planning tours would encourage tourists to visit again.

Since tourists expect to gain the most pleasure from their travel, offering such experiences, fulfilling the tourists' needs and forging some unexpected enjoyable travels are decisive elements in satisfying tourist expectations. Of these experiential values, the characteristics of rural life and culture are particularly attractive to tourists. Therefore, communities should not only emphasize 
the attraction of rural culture and natural scenery (Leask et al., 2013) but satisfy the experiential values of the destination for revisit decisions.

Funding: This study received no specific financial support.
Competing Interests: The authors declared that they have no conflict of interests.
Contributors/Acknowledgement: The work was supported by the 2014 Urban-Rural Communication
Project in Miaoli, Taiwan.
Views and opinions expressed in this study are the views and opinions of the authors, Asian Journal of
Agriculture and Rural Development shall not be responsible or answerable for any loss, damage or liability
etc. caused in relation to/arising out of the use of the content.

\section{References}

Antón, C., Camarero, C., \& Laguna-García, M. (2017). Towards a new approach of destination loyalty drivers: satisfaction, visit intensity and tourist motivations. Current Issues in Tourism, 20(3), 238-260. doi:10.1080/13683500.2014.936834.

Assaker, G., Vinzi, V. E., \& O'Connor, P. (2011). Examining the effect of novelty seeking, satisfaction, and destination image on tourists' return pattern: A two factor, non-linear latent growth model. Tourism Management, 32(4), 890-901. doi:10.1016/j.tourman.2010.08.004.

Cai, L. A., \& Combrink, T. E. (2000). Japanese female travelers a uniqueoutbound market. AsiaPacific Journal of Tourism Research, 5(1), 16-24.

Chew, E. Y. T., \& Jahari, S. A. (2014). Destination image as a mediator between perceived risks and revisit intention: A case of post-disaster Japan. Tourism Management, 40(2), 382-393. doi:10.1016/j.tourman.2013.07.008.

Choenkwan, S., Promkhambut, A., Hayao, F., \& Rambo, A. T. (2016). Does agrotourism benefit mountain farmers? a case study in Phu Ruea district, northeast Thailand. Mountain Research and Development, 36(2), 162-172. doi:10.1659/mrd-journal-d-15-00111.1.

Del Bosque, I. R., \& Martin, H. S. (2008). Tourist satisfaction - A cognitive-affective model. Annals of Tourism Research, 35(2), 551-573. doi:10.1016/j.annals.2008.02.006.

Ea, O., Ajani, E. N., \& Nenna, M. G. (2015). Constraints to brood and sell poultry production among farmers in Enugu State, Nigeria. Current Research in Agricultural Sciences, 2(2), 73-80.

Fan, X. T., \& Sivo, S. A. (2005). Sensitivity of fit indexes to misspecified structural or measurement model components: Rationale of two-index strategy revisited. Structural Equation Modeling-a Multidisciplinary Journal, 12(3), 343-367. doi:10.1207/s15328007sem1203_1.

Gannon, M. J., Baxter, I. W. F., Collinson, E., Curran, R., Farrington, T., Glasgow, S., \& Yalinay, O. (2017). Travelling for Umrah: destination attributes, destination image, and post-travel intentions. Service Industries Journal, 37(7-8), 448-465. doi:10.1080/02642069.2017.1333601.

Gunn, C. (1997). Vacationscape: Developing tourist areas (3rd ed.). New York: Routledge.

Hair, J. F., Black, W. C., Babin, B. J., \& Anderson, R. E. (2013). Multivariate data analysis (7th Edition) New Jersey: Pearson new international edition.

Holbrook, M. B. (1996). Special session summary: customer value-a framework for analysis and research. Advances in Consumer Research, 23(2), 138-142.

Holbrook, M. B., \& Hirschman, E. C. (1982). The experiential aspects of consumption: consumer fantasies, feelings, and fun. Journal of Consumer Research, 9(2), 132-140.

Huang, B. W., Chi, S. Y., \& Shen, Y. P. (2016). The Development Indicators and Strategies of Rural Rejuvenation. Journal of the Agricultural Association of Taiwan, 17(2), 215-230.

Jang, S. S., \& Feng, R. M. (2007). Temporal destination revisit intention: The effects of novelty seeking and satisfaction. Tourism Management, 28(2), 580-590. doi:10.1016/j.tourman.2006.04.024. 
Jepson, D., \& Sharpley, R. (2015). More than sense of place? Exploring the emotional dimension of rural tourism experiences. Journal of Sustainable Tourism, 23(8-9), 1157-1178. doi:10.1080/09669582.2014.953543.

Knobloch, U., Robertson, K., \& Aitken, R. (2017). Experience, emotion, and eudaimonia: a consideration of tourist experiences and well-being. Journal of Travel Research, 56(5), 651-662. doi:10.1177/0047287516650937.

Komppula, R., \& Gartner, W. C. (2013). Hunting as a travel experience: An auto-ethnographic study of hunting tourism in Finland and the USA. Tourism Management, 35, 168-180. doi:10.1016/j.tourman.2012.06.014.

Leask, A., Fyall, A., \& Barron, P. (2013). Generation Y: opportunity or challenge - strategies to engage Generation Y in the UK attractions' sector. Current Issues in Tourism, 16(1), 17 46. doi:10.1080/13683500.2011.642856

Lee, W., Sung, H., Suh, E., \& Zhao, J. L. (2017). The effects of festival attendees' experiential values and satisfaction on re-visit intention to the destination The case of a food and wine festival. International Journal of Contemporary Hospitality Management, 29(3), 10051027. doi:10.1108/ijchm-10-2015-0559.

Leiper, N. (1990). Tourist attraction systems. Annals of Tourism Research, 17(3), 367-384. doi:10.1016/0160-7383(90)90004-b.

Lin, J. H., Chen, T. Y., \& Liu, C. R. (2003). The inference of tourism image on tourist's behavioral intention on Taiwan's coastal scenic area: testing the mediating variable of tourists' satisfaction. Journal of Outdoor Recreation Study, 16(2), 1-22. doi:10.6130/jors.2003.16(2)1.

Liu, C. Z. (2008). Rural tourism and rural policies. Rural Tourism Research, 2(2), 1-10.

Mathwick, C., Malhotra, N., \& Rigdon, E. (2001). Experiential value: conceptualization, measurement and application in the catalog andinternet shopping environment. Journal of Retailing, 77(1), 39-56. http://dx.doi.org/10.1016/S0022-4359(00)00045-2.

McKercher, B., \& Koh, E. (2017). Do attractions "attract" tourists? The case of Singapore. International Journal of Tourism Research, 19(6), 661-671. doi:10.1002/jtr.2138.

Oppermann, M. (1996). Rural tourism in Southern Germany. Annals of Tourism Research, 23(1), 86-102. doi:10.1016/0160-7383(95)00021-6.

Pine, B. J., \& Gilmore, J. H. (1998). Welcome to the experience economy. Harvard Business Review, 76(4), 97-105.

Ritchie, J. R. B., Tung, V. W. S., \& Ritchie, R. J. B. (2011). Tourism experience management research Emergence, evolution and future directions. International Journal of $\begin{array}{llll}\text { Contemporary Hospitality } \quad \text { Management, } & \text { 23(4), }\end{array}$ doi:10.1108/09596111111129968.

Sameer, H., Girish, P., Robert Van Der, V., Songshan, H., \& Siripan, D. (2016). Mediating effects of place attachment and satisfaction on the relationship between tourists' emotions and intention to recommend. Journal of Travel Research, 56(8), 1079-1093. doi: $10.1177 / 0047287516678088$.

Schmitt, B., \& Zarantonello, L. (2013). Consumer experience and experiential marketing: a critical review. Review of Marketing Research, 10, 25-61.

Shen, C. C., Liao, J. T., \& Chou, C. Y. (2005). A study of the relationship among tourism experience, tourism image, satisfaction and loyalty-a case study of Gukeng Hua Shan. Journal of Outdoor Recreation Study, 18(3), 59-79. doi:10.6130/jors.2005.18(3)3.

Sheth, J. N., Newman, B. I., \& Gross, B. L. (1991). Why we buy what we buy: A theory of consumption values. Journal of Business Research, 22(2), 159-170.

Simelane, M. M., Masuku, M. B., Rugambisa, J. I., \& Earnshaw, D. M. (2016). Analysis of consumer willingness to pay for genetically modified maize food in Swaziland. International Journal of Sustainable Agricultural Research, 3(1), 19-28.

Swarbrooke, J. (2002). The development and management of visitor attractions. Oxford: Butterworth-Heinemann. Second edition. 
Weinberger, M. F., Zavisca, J. R., \& Silva, J. M. (2017). Consuming for an imagined future: middle-class consumer lifestyle and exploratory experiences in the transition to adulthood. Journal of Consumer Research, 44(2), 332-360. doi:10.1093/jcr/ucx045.

Westbrook, R. A. (1987). Product/Consumption-Based Affective Responses and Postpurchase Processes. Journal of Marketing Research, 24(3), 258-270. doi:10.2307/3151636.

Zeithaml, V. A., Berry, L. L., \& Parasuraman, A. (1996). The behavioral consequences of service quality. Journal of Marketing, 60(2), 31-46. doi:10.2307/1251929. 